\title{
Contextual Processing and the Impacts of Aging and Neurodegeneration: A Scoping Review
}

This article was published in the following Dove Press journal:

Clinical Interventions in Aging

\author{
Kim H Tran (D) ${ }^{1,2}$ \\ Andrew P McDonald ${ }^{1,3}$ \\ Ryan CN D'Arcy ${ }^{2,3}$ \\ Xiaowei Song id ${ }^{1,2}$ \\ 'Clinical Research Centre, Surrey \\ Memorial Hospital, Fraser Health \\ Authority, Surrey, BC, Canada; \\ ${ }^{2}$ Department of Biomedical Physiology \\ and Kinesiology, Simon Fraser University, \\ Burnaby, BC, Canada; ${ }^{3}$ Department of \\ Medicine, University of British Columbia, \\ Vancouver, BC, Canada
}

\begin{abstract}
Contextual processing (or context processing; CP) is an integral component of cognition. CP allows people to manage their thoughts and actions by adjusting to surroundings. CP involves the formation of an internal representation of context in relation to the environment, maintenance of this information over a period of time, and the updating of mental representations to reflect changes in the environment. Each of these functions can be affected by aging and associated conditions. Here, we introduced contextual processing research and summarized the literature studying the impact of normal aging and neurodegeneration-related cognitive decline on CP. Through searching the PubMed, PsycINFO, and Google Scholar databases, 23 studies were retrieved that focused on the impact of aging, mild cogniitve impairment (MCI), Alzheimer's disease (AD), and Parkinson's disease (PD) on CP. Results indicated that $\mathrm{CP}$ is particularly vulnerable to aging and neurodegeneration. Older adults had a delayed onset and reduced amplitude of electrophysiological response to information detection, comparison, and execution. MCI patients demonstrated clear signs of impaired CP compared to normal aging. The only study on AD suggested a decreased proactive control in $\mathrm{AD}$ participants in maintaining contextual information, but seemingly intact reactive control. Studies on PD restricted to non-demented older participants, who showed limited ability to use contextual information in cognitive and motor processes, exhibiting impaired reactive control but more or less intact proactive control. These data suggest that the decline in $\mathrm{CP}$ with age is further impacted by accelerated aging and neurodegeneration, providing insights for improving intervention strategies. This review highlights the need for increased attention to research this important but understudied field.

Keywords: Alzheimer's disease, Parkinson's disease, mild-cognitive impairment, aging, dementia, contextual processing, EEG-ERP, behavior
\end{abstract}

\section{Introduction}

Age-associated cognitive change can be a common part of normal aging, with declines in processing speed, inhibitory control, and working memory capacity being the archetypes. ${ }^{1}$ In accelerated aging with neurodegeneration such as Alzheimer's disease (AD), the most common form of late life dementia, cognitive changes are more drastic, affecting multiple domains including attention, executive function, decision-making, and memory. ${ }^{2,3}$ Similarly, Parkinson's disease (PD), a neurodegenerative disorder that leads to rigidity, bradykinesia, and imbalance, can also involve executive dysfunction and working memory deficits. ${ }^{4,5}$ Importantly, dementia often manifests from intermediate changes due to normal aging, known as mild cognitive impairment (MCI), ${ }^{6}$ which is a target for early detection and more effective early interventions. Multiple genetic and modifiable
Correspondence: Xiaowei Song I 3750 96th Avenue, Surrey, BC V3V IZ2, Canada

Tel + I 6045855666 ext. 774986

Email xiaowei.song@fraserhealth.ca

Clinical Interventions in Aging 2021:|6 345-36| 
lifestyle factors have been associated with long-term adverse health outcomes in aging. These include an unhealthy diet, smoking, alcoholism, obesity, and inactivity, and even the impact of adverse childhood experiences (ACE) can increase the risk of neurodegeneration and neuropsychiatric consequences in late adulthood. ${ }^{7,8}$

More directly related to the present paper, research has shown that contextual processing (CP, sometimes also referred to as context processing) is another important cognitive domain that can be greatly impaired during senescence. ${ }^{9} \mathrm{CP}$ entails the ability to process different streams of information to select the response that is most relevant for a certain context while inhibiting others for people to adapt to changing scenarios. CP reflects cognitive flexibility in that it depends on the functional integrity of the prefrontal cortex (eg, dorsolateral prefrontal cortex), ${ }^{4,10}$ through context activation/updating and context maintenance. ${ }^{11}$ The former is the ability to reactivate/ update context information on a trial-by-trial basis (ie, comparing the current to previously exposed information) whilst the latter reflects the working memory capacity to retain/activate/update the learned information. CP is utilized in various situations such as orienting one's self in space, adapting to novel scenarios, and facilitating decision-making processes, based on the general knowledge of certain objects, previously exposed information, and additional cues. $^{5,9,11}$ The capability of CP also allows people to select the responses for dealing with particular tasks with flexible behaviour adaptation. ${ }^{12}$

There is a gap in the literature regarding the impact of aging and neurodegeneration on CP. An apparent primary reason for this is that $\mathrm{CP}$ can be complexly presented, closely linked to many other well-studied cognitive skills. When evaluating cognitive performance, it may be difficult to differentiate a deficit oriented with $\mathrm{CP}$ from that with other cognitive skills such as executive function and memory retrieval. Even so, there are individual studies targeting a possible difference in CP performance between normal and accelerated aging. It is hypothesized that aging can lead to a reduction in CP performance, while neurodegeneration and dementia can cause a marked weakening in this cognitive domain.

The current lack of reviews to synthesize this information motivated our present research. Such knowledge is important in order to truly understand the relationship between neural substrates and disease sequelae, paving the way for more effective preventative and management strategies. The understanding is also critical for the development of portable technologies allowing for effective detection of brainwave changes in aging and dementia at point of care. ${ }^{13-15}$ The objective of this paper is to summarize the current literature on how normal and accelerated aging processes affect context processing.

To better prepare readers with the results, we start by introducing the key aspects of $\mathrm{CP}$ research.

\section{Contextual Processing Research}

\section{Proactive Control and Reactive Control of Contextual Processing}

Based on the "dual mechanism of cognitive control" (DMC) model, cognitive flexibility with $\mathrm{CP}$ is achieved through proactive control and/or reactive control, depending on the situational demands. ${ }^{16}$ Proactive control is a sustained, anticipatory form of control that allows individuals to respond efficiently and rapidly. Task-relevant information is held in working memory (ie, identity of previous stimuli and task instructions) to anticipate the upcoming stimuli. ${ }^{16}$ Proactive control is essentially maintaining contextual information in mind in order to respond appropriately to a certain scenario or task. For example, if a person is told to only respond when they see a certain cue-probe pair, ie, the word "animal" (cue) followed by the word "dog" as a probe, they must remember what the cue was while determining if it matches with the newlypresented probe. Being able to remember what the cue was allows individuals to respond faster when the correct probe is presented.

Reactive control on the other hand is used in situations where anticipating the upcoming stimuli does not yield optimal results or when the cue's predictability for the upcoming probe is unreliable. ${ }^{16}$ Reactive control helps individuals respond appropriately when facing unexpected stimuli and enables them to recognize incorrect information so that they can act accordingly in light of the novel information. For instance, a person would expect to see the word "dog" appear when the word "animal" is presented as a cue; however, the probe could be irrelevant objects, eg, house, car, and tree. When the cue is misleading the individual must use reactive control to suppress inappropriate actions.

\section{Neuroanatomical Basis of Contextual Processing}

The proactive and reactive controls of $\mathrm{CP}$ activate different brain regions and vary in the temporal pattern of neural 
activity. ${ }^{16-18}$ The proactive control is associated with the sustained activation of the lateral prefrontal cortex (PFC), reflecting the active maintenance of task goals and instructions. The hippocampus/medial temporal lobe is another neural region associated with proactive control because it helps maintain information online during working-memory tasks and binds task-relevant information to specific regions of the brain to elicit an appropriate response based on the presented stimulus. ${ }^{16}$ Previous research has also suggested that proactive control is linked to the dopaminergic system. More specifically, when a task-relevant stimulus is presented, phasic bursts of dopamine are synchronously released within the PFC. These phasic bursts dopamine release enables the PFC to be activated for longer periods of time, allowing contextual information to be maintained online for longer whilst protecting it from interference effects caused by task-irrelevant inputs. ${ }^{16-18}$

The reactive control, on the other hand, activates the lateral prefrontal cortex transiently whenever interference is detected, reflecting reactivation. Reactive control is also linked with the dopaminergic system but dopamine is not released in a phasic manner as seen in proactive control. ${ }^{16}$ The anterior cingulate cortex (ACC) that is involved in attention, conflict detection and monitoring has also been documented to be important for both proactive and reactive control. ${ }^{16,18}$

The dorsolateral PFC together with its association networks is key for $\mathrm{CP}$ regulation, due to several characteristics. $^{4,19-25}$ The PFC network regulates top-down processing by using contextual constraints or information cognitively stored to guide behaviours, modulates activity in other task-relevant areas for the selection of appropriate responses. PFC is highly interconnected with other cortical and subcortical areas such as parietal cortices, temporal lobes, and the basal ganglia, which are associated with sensory perception and movement initiation. ${ }^{19,22}$ Contextual information influences working memory via the lateral PFC, by extracting and transforming taskrelevant information into context representations. ${ }^{5,21,22,26}$ These multi-modal context representations are maintained in PFC to control both motor and sensory processes and enable the selection and implementation of appropriate actions depending on the context. ${ }^{22}$

\section{Electrophysiological Basis of Contextual Processing}

The event related potentials (ERP) derived from the electroencephalography (EEG) brain brainwaves are commonly used to understand the electrophysiological basis of CP. The ERP component P300 (P3), or more specifically the P3b component suggestive for target detection, is a known electrophysiological marker for $\mathrm{CP}^{26-29}$ Using the oddball target detection task, where infrequent targets are embedded in a series of frequent standard stimuli, ${ }^{30}$ a posterior-parietal scalp distribution of the $\mathrm{P} 3 \mathrm{~b}$ is elicited every time a target stimulus is detected. This indicates that the P3b plays a role in comparing environmental cues to contextual information, in that the person compares the current stimulus to the previous stimuli using working memory, ie, does the current stimulus match the cue that was previously seen. ${ }^{27,31}$ The P300 has also been associated with stimulus categorization and template matching of targets in working memory. ${ }^{32-34}$ There may be a recurrent link between working memory, $\mathrm{CP}$, and the $\mathrm{P} 3 \mathrm{~b}$ component, affected by allocation of attention to a stimulus, stimulus-task relevance and decision confidence. $^{35,36} \mathrm{P} 3 \mathrm{~b}$ latency is associated with the stimulus evaluation time to determine if the stimulus is taskrelevant, ${ }^{37-39}$ and with the mediation between perceptual analysis and response initiation to identify the stimulus and accordingly initiate a response. ${ }^{40} \mathrm{P} 3 \mathrm{~b}$ amplitude is modulated by attentional allocation and the task relevance of a stimulus. $^{35,36}$ Prolonged latencies and attenuated amplitudes of P3b have been shown in patients with neurologic conditions. $^{41}$

Another ERP component that has been linked to $\mathrm{CP}$ is $\mathrm{N} 2$, correlated with contextual encoding ${ }^{42}$ and reflecting the degree of attention required to process stimuli and conflict monitoring. ${ }^{43,44}$ The contingent negative variation (CNV) is another known ERP component associated with $\mathrm{CP}$, representing the maintenance of task-related information, ${ }^{45}$ and indexing stimulus expectation and motor preparation. ${ }^{46,47}$ Other ERP markers associated with CP include the lateralized readiness potential (LRP which is used to measure motor processes) and N2cc (an ERP component that prevents responses based on stimulus position involved in the Simon task). ${ }^{48,49}$

Moreover, researchers have attempted the utility of portable EEG-ERP technologies in the establishment of the brain vital sign framework in order to rapidly capture and evaluate the important brainwave markers, including consistent N400 characteristics during semantic information processing. ${ }^{13-15}$ By linking the previously reported N400 responses acquired using traditional laboratorybased experiments with the rapid bedside detection, this innovative research supports the development of rapid physiological-based measurements of higher cognitive 
functions such as $\mathrm{CP}$, without reliance on lab-based experimental probes for potential clinical translation. ${ }^{13-15}$

\section{Behavioral Tests for Contextual Processing}

The expectancy AX continuous performance test (AX$\mathrm{CPT}$ ) has been validated to index CP capacity. ${ }^{50}$ In the AX-CPT, subjects are asked to detect targets (X) and nontargets (non-X) within a steam of presented letters. The goal is to press the target button only when it is preceded by a certain letter, eg, " $\mathrm{A}$ ", which is the cue. For any nonA letters (referred to as "B cues"), subjects must inhibit themselves from pressing the target button even if followed by the letter X. Other versions of the AX-CPT include the "BX" and "AY trials," which test context maintenance and the capacity to overcome automatic responses, respectively.

The Stroop task is also often used to index CP, evaluating dynamic control, rule generation, and task switching. ${ }^{12}$ The task presents either a color or a word based upon a cue that precedes the stimulus, or a rule that is established at the beginning of a task, eg, "color" or "word". ${ }^{1,52}$ The color of the stimulus may be different from what it is written in, ie, the word "blue" filled with a "red" font color.

The garden path sentence task, Go no-go paradigm, stop-signal paradigm, and flanker interference are all used to examine inhibitory control. ${ }^{53-55}$ In the garden path sentence task, participants are instructed to remember a low-probability word ending, ie, the word "hair" instead of the word "teeth" for the phrase: "Before bed, remember to brush your [...]." ${ }^{53}$ After a delay interval, they are asked to recall the low-probability ending word for the phrases that were shown to them prior to the delay. In the go no-go task, participants are asked to refrain themselves from responding to a low-frequency target stimulus, with fewer errors signifying a better response inhibition. ${ }^{55}$ A variation of the go no-go task asks the participants to alternate between a letter categorization task (deciding if a vowel was present) and a number categorization task (deciding if an even number was present), and to respond only if a vowel or an even number were present. ${ }^{56}$ In a similar version of the go no-go paradigm participants are asked to reach for a target when they saw a specific cue appearing on the screen. ${ }^{57}$ In the stop-signal task, participants are asked to suppress an action when instructed, ie, when a certain tone is presented. ${ }^{54}$ In the flanker interference test, participants are asked to press a keyboard button that corresponds to the direction the central target is facing - sometimes the central target faces a direction that is opposite to the peripheral items (flankers) - the goal is to respond as quickly as possible without being distracted. ${ }^{58}$

In the counting distraction-attention task, ${ }^{59}$ participants are asked to press a letter that corresponds to the correct number of digits presented. For instance, in the congruent condition, one of the digits 1-4 are presented, ie, "10;" the number and the amount of correct digits present match (in this case, the cue contains the number 1 and only one of the four allowed numbers is present). ${ }^{59}$ In the incongruenteligible condition, the number and identity of the digits did not match, ie, "33;" the number 3 is correct but this cue only has two of the allowed numbers. ${ }^{59}$ In the auditoryvisual distraction-attention task, participants are presented with auditory and visual stimuli and are asked to focus solely on one stimulus, testing their task-switching and execution abilities. ${ }^{60}$

In the predictive sequence visual task participants are instructed to use the preceding information (series of triangles moving from left, upwards, and right) to anticipate the target (downward facing triangle). ${ }^{24}$ The multi-finger sequencing task, on the other hand, is used to study the ability to overcome automatic responses. ${ }^{61}$ Participants press a keyboard button that corresponds to the color of a block, ie, "m" key for red box and "n" key for blue box, and the colored blocks are presented in different orders. ${ }^{61}$

In the Simon task, subjects are asked to respond to a non-spatial feature of a lateralized stimulus while ignoring its position (ie, when the word "left" is presented on the right side of the screen, they need to press the keyboard button that corresponds to the word irrespective of its position). ${ }^{62}$

\section{Contextual Processing Execution in Relation to Other Aspects of Cognition}

$\mathrm{CP}$ is a component of executive function and working memory. ${ }^{4,5}$ When there is a delay between task-relevant stimuli and the generation of a response, contextual information is maintained over time and facilitates working memory. ${ }^{5,63}$ In the daily environment, sequences of events separated in time are integrated and actively maintained in working memory to help guide actions. ${ }^{19}$ Contextual information also mirrors the series of events that are separated in time, which are then integrated by working memory into 
predictive goal-relevant information. These are short predictive sequences of stimuli that precede the target event, ie, symbols, words, or patterns, which the individual then uses to react accordingly. ${ }^{19}$

When engaging in $\mathrm{CP}$, people first comprehend the taskrelevant (predictive) stimuli, detect the stimuli, and translate this information into a self-guided cue, and utilize this information to generate a response (eg, whether to click the target button or non-target button in the AX-CPT task). According to Baddeley's model of working memory, contextual information is analogous to the sequential visual or auditory stimuli that are stored in the visuospatial sketchpad and phonological loop, which are transformed by the central executive system into goal-relevant predictive information. ${ }^{64}$

\section{Methods}

Two reviewers (K.H.T and A.M) independently conducted a literature search using PubMed (MEDLINE), Google Scholar, and PsycINFO up to September 2020. We focused on these databases because of their established reputation and coverage on biomedical and clinical research. Studies were reviewed and any contentions were resolved by involving a third reviewer (X.S). The majority opinion of the reviewers was used for further analysis.
The sets of keyword search terms were used in combination and included ("context processing" OR "contextual processing" OR "proactive control" OR "reactive control") AND ("aging” OR “aging” OR "senior” OR “elderly" OR "older adults" OR "mild cognitive impairment" OR "MCI" OR ("dementia" OR "vascular dementia” OR "frontotemporal dementia" OR "Parkinson's" OR "PD” OR "Lewy body dementia" OR "LBD” OR “Alzheimer's Disease" OR “AD”). The “*” was used to indicate multiple words of the same meaning but different endings (Figure 1).

The search yielded a total of 803 articles. After filtering for title/abstract containing contextual processing key terminology, language filter (for English), and age (for older adults), 137 articles remained in the filtered set I. A further filtering step through article reading excluded studies focusing on memory, attention, visuospatial, language, semantic, processing, or other neurodegenerative diseases unrelated to dementia. The final filtered set contained 23 articles, including 11 on normal aging, 1 on $\mathrm{AD}, 5$ on PD, and 6 on MCI (Figure 1).

This study applied narrative descriptions to each of the final articles, while no quality appraisal was performed given the relatively small number of studies found and the varied research methods and objectives of the studies.

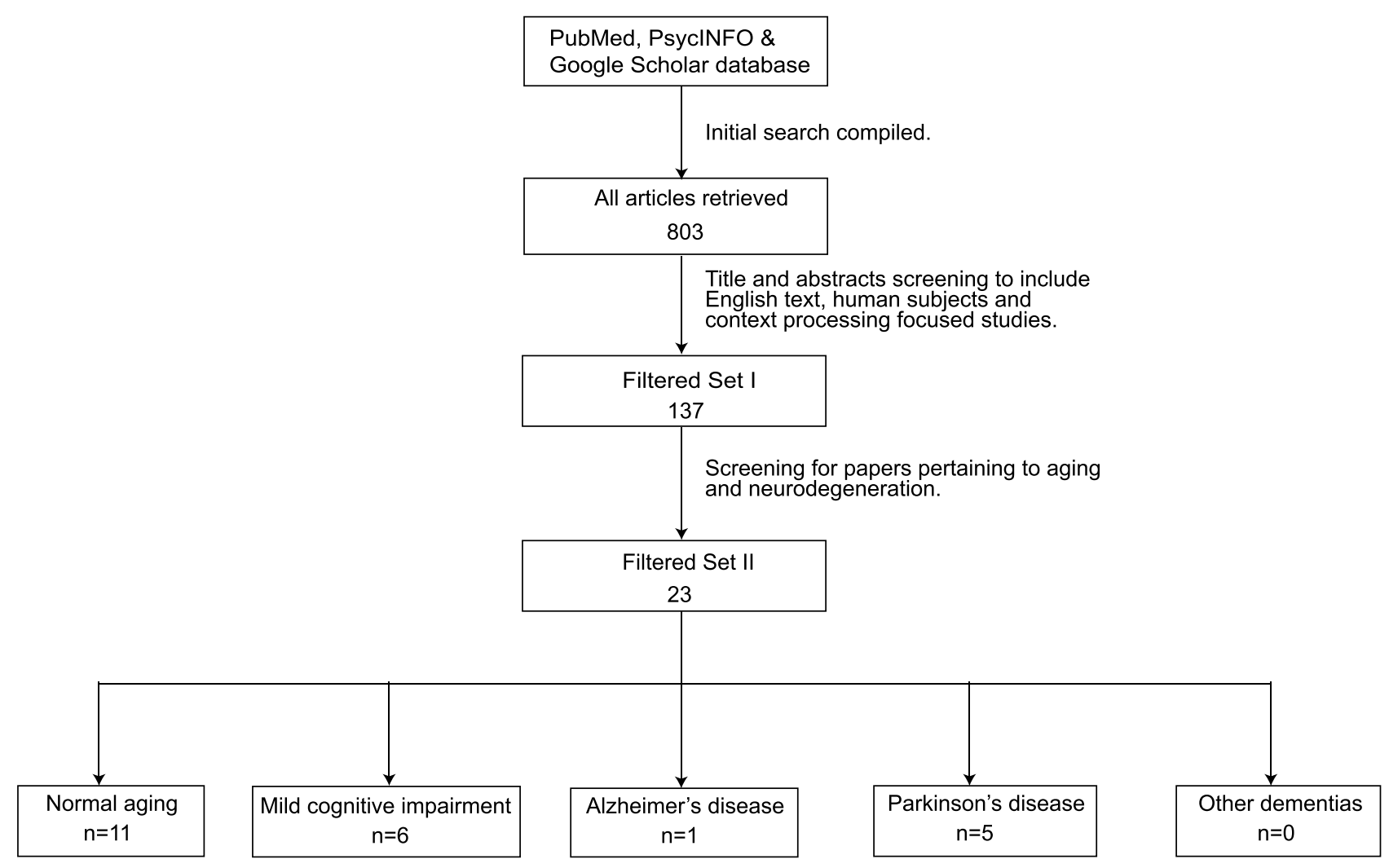

Figure I The literature search and article selection process. 


\section{Results}

\section{Aging and Contextual Processing - Electrophysiology Data}

Studies suggested differences in the ERP components (P300 and $\mathrm{CNV}$ ) between older adults and adolescents/younger adults (Table 1A). Older adults exhibited a delayed P3b onset, indicating a deficit in making an anticipatory response towards a stimulus ${ }^{65}$ while taking a longer time to execute a response. ${ }^{40,66,67}$ Older adults showed comparable P3b amplitudes on context-dependent and context-independent trials, suggesting inability to differentiate contextual relevant versus irrelevant information. ${ }^{10}$ A reduced amplitude and a delayed onset in P3b were also observed when presented with conflicting stimuli, confirming difficulties in processing and responding to unexpected stimuli. ${ }^{65}$ Older adults also exhibited a P3a component after a non-cue stimulus (irrelevant item), which was not seen in younger participants, demonstrating involuntary and transient allocation of attention to unexpected or novel stimuli, ${ }^{30,68,69}$ and indicating increased susceptibility to attentional distraction with a longer reaction time. ${ }^{70}$ When there was a delay between the presentation of the cue and the probe, older adults showed a lower CNV amplitude compared to younger adults, demonstrating a decline in neural correlate of task maintenance and motor preparation in anticipation of a stimulus. ${ }^{71}$ Hajra et al (2018) used portable EEG/ERP technology and demonstrated the correlation of context-related information processing with increased N400 amplitude and increased temporoparietal activity while developing the brain vital sign framework in a wide age range. ${ }^{13,14}$

\section{Aging and Contextual Processing - Behavioral and Neuroanatomical Data}

Studies suggested that aging involves different neural activation patterns in the inhibitory processes concerning proactive control and reactive control (Table 1A). When suppressing irrelevant information or engaging in conflict resolution, older adults exhibited increased activity in multiple brain regions for inhibitory processes (eg, left inferior frontal triangularis, left inferior frontal operculum, left inferior temporal, and right anterior striatum) and displayed reduced efficiency; ${ }^{72,73}$ whereas younger adults only saw an increase in activity in their left posterior superior temporal. ${ }^{74}$

When older adults engaged in proactive control, they exhibited decreased activity in the anterior cingulate cortex bilaterally (associated with conflict detection) ${ }^{75,76}$ and increased activity in the middle frontal gyrus (MFG), ${ }^{74}$ linked with maintenance of task-relevant information. ${ }^{17}$ The trade-off in activity (increased MFG activity at the expense of ACC activity) was interpreted as beneficial for older adults in tasks where proactive control is required. ${ }^{17}$ In reactive control, older adults recruited the left inferior frontal operculum (known to play a role in inhibitory processes) more than the younger subjects. ${ }^{74}$ Studies also showed that older adults tend to rely more on the prefrontal structures (Table 1A). Younger adults only recruited frontal structures during mixed block trials in which they alternated between multiple tasks with cognitive challenge. ${ }^{71}$ In contrast, older adults recruited the same amount of frontal structures when completing a simpler task. $^{71}$ Similarly, when completing the AX-CPT, older adults used the lateral PFC more than younger adults. ${ }^{77}$ In addition, older adults showed variable PFC activation patterns when engaging in proactive and reactive control: in proactive control, the activation of the right dorsolateral PFC (key for memory encoding and goal-maintenance) was decreased; in reactive control, the activation in the ventral PFC and inferior frontal junction (important for reactive control) was increased. ${ }^{16,74}$ This suggests that normal aging involves reactive control more than proactive control. ${ }^{10,17,77-81}$

\section{$\mathrm{MCl}$ on Contextual Processing - Electrophysiology Data}

The six studies each examined amnestic MCI (Table 1B). Patients with multiple domain amnestic mild cognitive impairment (mdaMCI), in which memory is affected in conjunction with other cognitive aspects, exhibited longer reaction times and fewer correct responses on several cognitive control tasks (eg, Simon task, go no go-task, and auditory-visual distraction attention task). ${ }^{82-87}$ Patients with single domain amnestic mild cognitive impairment (sdaMCI), in which only memory is impaired, performed at an intermediate level relative to mdaMCI and age-matched controls. $^{82-87}$ It also took the sdaMCI patients a longer time to evaluate and classify the items compared to the controls, shown by the longer P3b latencies. $^{83}$ Both mdaMCI and sdaMCI patients had lower LRP amplitude than the control group, indicating a deficit in their ability to select and prepare for a motor response. $^{85}$ mdaMCI patients also showed longer N2cc latencies (an ERP component that examines executive functions), in contrast to sdaMCI and control patients. ${ }^{86}$ 
Table I Summary of Publications Reviewed in This Study

\begin{tabular}{|c|c|c|c|c|c|}
\hline $\begin{array}{l}\text { First } \\
\text { Author }\end{array}$ & $\begin{array}{l}\text { Year of } \\
\text { Publication }\end{array}$ & $\begin{array}{l}\text { Subject } \\
\text { [Mean Age (sd } \\
\text { or Range)] }\end{array}$ & $\begin{array}{l}\text { Study } \\
\text { Method }\end{array}$ & Task(s) Involved & Main Findings \\
\hline \multicolumn{6}{|c|}{ (A) Normal Aging } \\
\hline Braver $^{81}$ & 2001 & $\begin{array}{l}\text { YA }[24.6(5.5)] \\
\mathrm{n}=175 \\
\text { OA }[72.0(5.1)] \\
\mathrm{n}=8 \mathrm{I}\end{array}$ & Behavioural & AX-CPT & $\begin{array}{l}\text { OA performed poorly on the } B X \text { and } A X \text { trials of the AX-CPT; } \\
\text { they had impaired proactive control and were unable to use the } \\
\text { cue as efficiently as the YA group to anticipate the upcoming } \\
\text { target. However, OA performed faster on } A Y \text { trials, suggesting } \\
\text { preserved reactive control. }\end{array}$ \\
\hline Rush $^{79}$ & 2006 & $\begin{array}{l}\text { YA [19.8(1.9)]; } \\
\mathrm{n}=51 \\
\text { OA }[74.8(4.3)] \\
\mathrm{n}=56\end{array}$ & Behavioural & $\begin{array}{l}\text { AX-CPT, Stroop, garden } \\
\text { path sentences, go no-go, } \\
\text { and stop-signal task }\end{array}$ & $\begin{array}{l}\text { Compared to } Y A, O A \text { made fewer errors on } A Y \text { trials, indicating } \\
\text { intact reactive control in responding to novel stimuli. OA also had } \\
\text { a longer reaction time relative to } Y A \text { on } B X \text { trials, which required } \\
\text { proactive control. } O A \text { also had trouble inhibiting inappropriate } \\
\text { responses for stop-signal and Stroop task. YA and OA performed } \\
\text { similarly on the garden path and go no-go tasks. }\end{array}$ \\
\hline West $^{71}$ & 2006 & $\begin{array}{l}\text { YA }[20.50 \\
(0.61)] ; n=20 \\
\text { OA }[71.75 \\
(7.79)] ; n=20\end{array}$ & $\begin{array}{l}\text { Behavioural } \\
\text { and EEG }\end{array}$ & Counting task & $\begin{array}{l}\text { OA responded more slowly when they attempted to maintain contextual } \\
\text { information over a longer period of time ( } 5000 \mathrm{~ms} \text { vs } 2000 \mathrm{~ms}) \text {, showing } \\
\text { a decrease in contingent negative variation amplitude. OA also needed } \\
\text { additional cognitive loads for tasks that were relatively easy for YA. }\end{array}$ \\
\hline Paxton $^{77}$ & 2008 & $\begin{array}{l}\text { Experiment I: } \\
\text { YA [22.8 (3.7)]; } \\
n=21 \\
\text { OA [73(5.7)]; } \\
n=20 \\
\text { Experiment } 2: \\
\text { YA [21.56 } \\
(3.14)] ; n=16 \\
\text { OA }[72.38 \\
(6.51)] ; n=16\end{array}$ & $\begin{array}{l}\text { Event- } \\
\text { related fMRI }\end{array}$ & AX-CPT & $\begin{array}{l}\text { Experiment I: OA had increased errors and reaction times on } B X \\
\text { trials, but less errors and faster reaction times on } A Y \text { trials than YA. } \\
\text { OA had greater activity in their lateral PFC when performing this } \\
\text { task, compared to YA. } \\
\text { Experiment 2: OA displayed sustained activity in the anterior and } \\
\text { posterior brain regions whereas YA only showed transient activity } \\
\text { in these regions. During cue-related activity, OA exhibited reduced } \\
\text { activity in the right dorsolateral PFC, suggesting impaired ability to } \\
\text { encode/maintain information. }\end{array}$ \\
\hline De Sanctis ${ }^{96}$ & 2009 & $\begin{array}{l}\text { YA [24.1 } \\
(20-35)] ; n=15 \\
\text { HP OA }[70 \\
(66-82)] ; n=10 \\
\text { LP OA }[69.7 \\
(66-82)] ; n=9\end{array}$ & EEG & $\begin{array}{l}\text { Letter and number } \\
\text { categorization task }\end{array}$ & $\begin{array}{l}\text { LP OA showed a reduced P3 activity over the centro-parietal } \\
\text { regions whereas the HP OA showed a robust P3, with the latter } \\
\text { group exhibiting more robust activity in their PFC. This suggests } \\
\text { a correlation of maintaining high levels of executive function and } \\
\text { PFC activity in OA. }\end{array}$ \\
\hline Fogelson ${ }^{65}$ & 2010 & $\begin{array}{l}\text { YA [24]*; } n=12 \\
\text { OA [65]*; } n=11\end{array}$ & EEG & $\begin{array}{l}\text { Predictive Sequence Visual } \\
\text { Task }\end{array}$ & $\begin{array}{l}\text { OA exhibited a greater P3b latency in contrast to YA. OA also } \\
\text { exhibited a late sustained positivity after the detection of predicted and } \\
\text { random targets, indicating their uncertainties in making decisions. }\end{array}$ \\
\hline Hämmerer $^{70}$ & 2010 & $\begin{array}{l}C[10.15(0.59)] ; \\
\mathrm{n}=42 \\
\mathrm{~A}[14.42(0.55)] ; \\
\mathrm{n}=44 \\
\text { YA [24.27 } \\
(2.07)] ; \mathrm{n}=46 \\
\text { OA [71.24 } \\
(2.91)] ; \mathrm{n}=47\end{array}$ & EEG & AX-CPT & $\begin{array}{l}\text { C, A and YA participants paid more attention to the Cue stimulus } \\
\text { in contrast to the Non-Cue stimulus as shown by the increased P3 } \\
\text { amplitude for the former. OA on the other hand were the only } \\
\text { ones that exhibited a spike in their P3a amplitude for the Non-cue } \\
\text { stimulus, suggesting increased attentional distractibility. }\end{array}$ \\
\hline Trewartha ${ }^{95}$ & 2013 & $\begin{array}{l}\text { YA }[22.4(2.8)] \\
\mathrm{n}=17 \\
\text { OA }[72.3(5.0)] \\
\mathrm{n}=15\end{array}$ & EEG & $\begin{array}{l}\text { Multi-finger sequencing } \\
\text { task }\end{array}$ & $\begin{array}{l}\text { OA's P3b amplitude was reduced and its onset was delayed } \\
\text { compared to YA when presented with conflicting stimuli, indicating } \\
\text { reduced ability to differentiate task-relevant from distractor items. } \\
\text { YA had larger P3b amplitudes in trials where they responded faster, } \\
\text { suggesting better context updating in correlation with faster task } \\
\text { execution. }\end{array}$ \\
\hline
\end{tabular}


Table I (Continued).

\begin{tabular}{|c|c|c|c|c|c|}
\hline $\begin{array}{l}\text { First } \\
\text { Author }\end{array}$ & $\begin{array}{l}\text { Year of } \\
\text { Publication }\end{array}$ & $\begin{array}{l}\text { Subject } \\
\text { [Mean Age (sd } \\
\text { or Range)] }\end{array}$ & $\begin{array}{l}\text { Study } \\
\text { Method }\end{array}$ & Task(s) Involved & Main Findings \\
\hline Bugg $^{78}$ & 2014 & $\begin{array}{l}\text { Experiment I: } \\
\text { YA [19.20 } \\
(1.04)] ; n=16 \\
\text { OA [74.68 } \\
(6.32)] ; n=25 \\
\text { Experiment } 2: \\
\text { YA [19.20 } \\
(1.04)] ; n=25 \\
\text { OA [70.00 } \\
(5.93)] ; n=17\end{array}$ & Behavioural & $\begin{array}{l}\text { Stroop task and flanker } \\
\text { interference }\end{array}$ & $\begin{array}{l}\text { Experiment I: OA performed similarly to YA in trials where there } \\
\text { was a high level of interference. However, in trials with low } \\
\text { interference, OA performed much worse than YA. This suggests } \\
\text { that when faced continuously with conflicting information, OA are } \\
\text { able to use their reactive control to select the appropriate } \\
\text { response and that their reactive control is relatively similar to YA. } \\
\text { Experiment 2: both YA and OA demonstrated less flanker } \\
\text { interference when stimuli were presented in trials with high levels } \\
\text { of interference in contrast with trials with low levels of } \\
\text { interference. }\end{array}$ \\
\hline Schmitt ${ }^{10}$ & 2014 & $\begin{array}{l}\text { YA [22.4 (2.4)]; } \\
n=18 \\
\text { OA }[75.1(3.8)] \\
n=18\end{array}$ & $\begin{array}{l}\text { Behavioural } \\
\text { and EEG }\end{array}$ & AX-CPT & $\begin{array}{l}\text { In YA, P3b amplitude increased from frontal to parietal electrodes } \\
\text { mainly on the context-dependent trials. OA, instead, exhibited } \\
\text { comparable P3b amplitudes on context-dependent and context- } \\
\text { independent trials, suggesting that OA were more easily distracted } \\
\text { by irrelevant stimuli in contrast to YA. }\end{array}$ \\
\hline Manard $^{74}$ & 2017 & $\begin{array}{l}\text { YA [23.5(3.22)]; } \\
\mathrm{n}=20 \\
\text { OA [65.I(3.8)]; } \\
\mathrm{n}=20\end{array}$ & $\begin{array}{l}\text { Event- } \\
\text { related fMRI }\end{array}$ & Stroop task & $\begin{array}{l}\text { OA exhibited increased activity in the left inferior frontal areas and } \\
\text { the anterior striatum when engaged in conflict resolution and } \\
\text { suppressing of irrelevant information. When engaged in proactive } \\
\text { control, OA exhibited increased activity in the middle frontal } \\
\text { gyrus. OA also recruited the left inferior frontal operculum more } \\
\text { than YA for reactive control. }\end{array}$ \\
\hline \multicolumn{6}{|c|}{ (B) Mild Cognitive Impairment (MCl) } \\
\hline Cespón ${ }^{85}$ & 2013 & $\begin{array}{l}\mathrm{mdaMCl}[71.0 \\
(9.2)] ; \mathrm{n}=13 \\
\text { sdaMCl }[67.0 \\
(9.1)] ; \mathrm{n}=17 \\
\text { Control }[65.0 \\
(8.1)] ; \mathrm{n}=25\end{array}$ & $\begin{array}{l}\text { Behavioural } \\
\text { and EEG }\end{array}$ & Simon task & $\begin{array}{l}\text { mdaMCl patients exhibited more errors in the Simon task } \\
\text { compared to the other two groups. In addition, the N2pc } \\
\text { amplitude (ERP marker associated with visuospatial processes) was } \\
\text { smaller in the mdaMCl group compared to controls. Lastly, both } \\
\text { mdaMCl and sdaMCl patients had a lower LRP amplitude (an ERP } \\
\text { marker for motor processes) than control groups. }\end{array}$ \\
\hline $\begin{array}{l}\text { Cid- } \\
\text { Fernández }\end{array}$ & 2014 & $\begin{array}{l}\text { aMCI [69.5 } \\
(8.2)] ; n=30 \\
\text { Control [65.9 } \\
(8.0)] ; n=63\end{array}$ & $\begin{array}{l}\text { Behavioural } \\
\text { and } E E G\end{array}$ & Go no-go task & $\begin{array}{l}\text { a MCl patients had longer reaction times and less accuracy in the } \\
\text { Go no-go task in contrast to the control group. a MCl patients also } \\
\text { had lower } \mathrm{N} 2 \text { amplitudes for the Go no-go task compared to } \\
\text { controls, which indicated that they were less skilled at detecting } \\
\text { task-relevant stimulus and inhibiting inappropriate responses. }\end{array}$ \\
\hline Cespón 86 & 2015 & $\begin{array}{l}\text { mdaMCl [7I.2 } \\
(2.06)] ; n=12 \\
\text { sdaMCl }[69.1 \\
(1.98)] ; n=13 \\
\text { Control [68.3 } \\
(1.68)] ; n=18\end{array}$ & $\begin{array}{l}\text { Behavioural } \\
\text { and } E E G\end{array}$ & Simon task & $\begin{array}{l}\text { The mdaMCl patients made more errors on the Simon task than the } \\
\text { sdaMCl patients and the controls. This was supported by the EEG } \\
\text { data, showing that the mdaMCl group had longer } \mathrm{N} 2 \mathrm{cc} \text { latencies, ie, } \\
\text { ERP markers for selective attention in tactile processes. }\end{array}$ \\
\hline $\begin{array}{l}\text { Ramos- } \\
\text { Goicoa }^{83}\end{array}$ & 2016 & $\begin{array}{l}\text { aMCI }[70.7 \\
(9.1)] ; n=39 \\
\text { Control }[65.4 \\
(9.2)] ; n=45\end{array}$ & $\begin{array}{l}\text { Behavioural } \\
\text { and EEG }\end{array}$ & Stroop task & $\begin{array}{l}\text { aMCl patients struggled with selecting and preparing for a motor } \\
\text { response (lower LRP amplitudes relative to control group). aMCl } \\
\text { patients also evaluated and classified congruent and incongruent } \\
\text { stimuli more slowly than controls, as shown by the longer P3b } \\
\text { latencies. }\end{array}$ \\
\hline
\end{tabular}

(Continued) 
Table I (Continued).

\begin{tabular}{|c|c|c|c|c|c|}
\hline $\begin{array}{l}\text { First } \\
\text { Author }\end{array}$ & $\begin{array}{l}\text { Year of } \\
\text { Publication }\end{array}$ & $\begin{array}{l}\text { Subject } \\
\text { [Mean Age (sd } \\
\text { or Range)] }\end{array}$ & $\begin{array}{l}\text { Study } \\
\text { Method }\end{array}$ & Task(s) Involved & Main Findings \\
\hline $\begin{array}{l}\text { Cid- } \\
\text { Fernández }{ }^{84}\end{array}$ & 2017 & $\begin{array}{l}\mathrm{mdaMCl}[72.1 \\
(6.9)] ; \mathrm{n}=12 \\
\text { sdaMCl }[68.7 \\
(10.1)] ; \mathrm{n}=22 \\
\text { Control }[67.0 \\
(9.8)] ; \mathrm{n}=20\end{array}$ & $\begin{array}{l}\text { Behavioural } \\
\text { and } E E G\end{array}$ & $\begin{array}{l}\text { Auditory-visual distraction- } \\
\text { attention task }\end{array}$ & $\begin{array}{l}\text { mdaMCl group performed the worst out of all the } 3 \text { groups, with } \\
\text { longer reaction times and more incorrect responses. sdaMCl } \\
\text { group performed at an intermediate level relative to control and } \\
\text { mdaMCl. }\end{array}$ \\
\hline $\begin{array}{l}\text { Cid- } \\
\text { Fernández }{ }^{87}\end{array}$ & 2017 & $\begin{array}{l}\text { mdaMCl }[72.3 \\
(7.3)] ; n=12 \\
\text { sdaMCl }[68.3 \\
(10.1)] ; n=21 \\
\text { Control }[66.2 \\
(9.2)] ; n=19\end{array}$ & $\begin{array}{l}\text { Behavioural } \\
\text { and EEG }\end{array}$ & $\begin{array}{l}\text { Auditory-visual distraction- } \\
\text { attention task }\end{array}$ & $\begin{array}{l}\text { mdaMCl group had longer reaction times and fewer correct } \\
\text { responses than control and sdaMCl groups. mdaMCl group had } \\
\text { lower sLRP amplitudes in contrast to control participants whereas } \\
\text { sdaMCI had longer sLRP peak latencies (ERP marker for motor } \\
\text { processes). }\end{array}$ \\
\hline \multicolumn{6}{|c|}{ (C) Alzheimer's Disease } \\
\hline Braver $^{88}$ & 2005 & $\begin{array}{l}\text { YA [19.8(1.9)]; } \\
n=51 \\
\text { YO [7I.7(2.3)]; } \\
n=46 \\
O O[81.0(4.7)] \\
n=43 \\
\text { AD [80.1 (7.I)]; } \\
n=26\end{array}$ & Behavioural & AX-CPT & $\begin{array}{l}\text { Compared with YA, YO experienced issues related to context } \\
\text { activation/updating but no additional impairment in context } \\
\text { maintenance. Individuals between the ages of } 66-75 \text { appeared to } \\
\text { be more vulnerable to context activation/updating deficits. In } \\
\text { contrast, } O O \text { performed worse in the long-delay condition } \\
\text { ( } 5000 \mathrm{~ms} \text { ) in contrast to the YO, suggesting increased deficits in } \\
\text { context maintenance at advanced ages. Additionally, individuals } \\
\text { with very mild AD demonstrated even greater level of context } \\
\text { maintenance deficits, compared to age-matched } O O \text {. }\end{array}$ \\
\hline \multicolumn{6}{|c|}{ (D) Parkinson's Disease (on Non-Demented Older Patients) } \\
\hline Wylie $^{91}$ & 2010 & $\begin{array}{l}\text { OAP }[65.9(8.2)] \\
\mathrm{n}=52 \\
\text { OA }[63.3(7.9)] \\
\mathrm{n}=30\end{array}$ & Behavioural & Simon task & $\begin{array}{l}\text { OAP and OA controls performed similarly on tasks requiring on- } \\
\text { line control (ie suppressing incorrect responses within one trial/at } \\
\text { a given moment in time). OAP performed as well as OA on tasks } \\
\text { requiring proactive control (adjusting control mechanisms to } \\
\text { better adapt to future response conflict). On-line cognitive control } \\
\text { was more affected as mobility-related impairments increased } \\
\text { amongst OAP patients, whereas proactive control remained } \\
\text { unaffected. }\end{array}$ \\
\hline Fogelson ${ }^{89}$ & 2011 & $\begin{array}{l}\text { OAP }[61.6(5.6)] \\
n=8 \\
\text { OA }[63.4(6.2)] \\
n=8\end{array}$ & $\begin{array}{l}\text { Behavioural } \\
\text { and EEG }\end{array}$ & $\begin{array}{l}\text { Predictive sequence visual } \\
\text { task }\end{array}$ & $\begin{array}{l}\text { OA processed random and predicted targets differently whereas } \\
\text { OAP showed no difference in performance, as shown by the lack } \\
\text { of P3b latency shift between the two trials for OAP patients. OA } \\
\text { also processed predicted targets faster than random targets but } \\
\text { this was not observed in OAP. OAP patients were able to detect } \\
\text { targets but experienced difficulties with differentiating task- } \\
\text { relevant vs task-irrelevant information. }\end{array}$ \\
\hline Fogelson ${ }^{25}$ & 2013 & $\begin{array}{l}\text { OAP }[58.8(2.3)] \\
n=15 \\
\text { OA }[58.3(2.8)] \\
n=15\end{array}$ & EEG & $\begin{array}{l}\text { Predictive sequence visual } \\
\text { task }\end{array}$ & $\begin{array}{l}\text { OAP patients had higher cluster coefficients and longer path } \\
\text { lengths, demonstrating weaker frontal-parietal connections when } \\
\text { performing target detection tasks. This was because high cluster } \\
\text { coefficients and long path lengths are correlated with increased } \\
\text { functional connections within the frontal loops, indicating less } \\
\text { neurons/networks to support communications between the } \\
\text { frontal and other cortical regions. }\end{array}$ \\
\hline
\end{tabular}

(Continued) 
Table I (Continued).

\begin{tabular}{|l|l|l|l|l|l|}
\hline $\begin{array}{l}\text { First } \\
\text { Author }\end{array}$ & $\begin{array}{l}\text { Year of } \\
\text { Publication }\end{array}$ & $\begin{array}{l}\text { Subject } \\
\text { [Mean Age (sd } \\
\text { or Range)] }\end{array}$ & $\begin{array}{l}\text { Study } \\
\text { Method }\end{array}$ & Task(s) Involved & Main Findings \\
\hline Li $^{90}$ & 2018 & $\begin{array}{l}\text { OAP [58.1 (2.5)]; } \\
\mathrm{n}=17 \\
\text { OA [57 (2.6)]; } \\
\mathrm{n}=15\end{array}$ & EEG & $\begin{array}{l}\text { Predictive sequence visual } \\
\text { task }\end{array}$ & $\begin{array}{l}\text { OAP patients showed similar P3b amplitude across the implicit and } \\
\text { explicit trials (when they were made aware of the predictive } \\
\text { sequence and the subsequent target), whereas OA had higher P3b } \\
\text { amplitudes for the explicit condition. OAP also exhibited longer } \\
\text { P3b latencies for predicted targets compared to random targets in } \\
\text { both the implicit and explicit sessions, indicating slower processing } \\
\text { speed of predicted targets. OAP also had high degree of } \\
\text { connectivity between neural networks (the gamma measurements) } \\
\text { when processing contextual information, indicating functional } \\
\text { connectivity abnormalities within their top-down frontal networks. }\end{array}$ \\
\hline Di Caprio 92 & 2020 & $\begin{array}{l}\text { RPD [57.6 (6.8)]; } \\
n=17 \\
\text { LPD [61.6 (5.6)]; } \\
n=17 \\
\text { Controls [58.8 } \\
(6.9)] ; n=24\end{array}$ & Behavioural & Reaching stop-signal task & $\begin{array}{l}\text { Reactive inhibition (ability to immediately stop a behaviour) was } \\
\text { reduced in early-stage PD patients (Hoehn and Yahr stage I) } \\
\text { whereas proactive inhibition (ability to shape response strategies } \\
\text { according to the context) remained unaffected. }\end{array}$ \\
\hline
\end{tabular}

Notes: *No age range or standard deviations were provided. " $n$ " indicates the sample size.

Abbreviations: A, adolescents; AD, Alzheimer's disease; aMCl, amnestic mild cognitive impairment; $A X-C P T, A X$ continuous performance test; $A Y$, a variation of the AX-CPT; BX, a variation of the AX-CPT; C, children; EEG, electroencephalography; fMRI, functional magnetic resonance imaging; HP, high-performing; LP, low-performing; LPD, left-dominant Parkinson's disease patients; LRP, lateralized readiness potential; mdaMCl, multiple domain amnestic mild cognitive impairment; N2, an event-related potential associated with detecting mismatched information; N2cc; an event-related potential associated with selective attention in tactile processes; N2pc, an event-related potential associated with selective attention in visuospatial processes; OA, older adults; OAP, older adults with Parkinson's Disease; OO, old-old adults; P3, an event-related potential associated with decision making; P3a, a component of the P3 that is associated with processing unexpected novel stimuli; P3b, a component of the P3 that is associated with information processing; RPD, right-dominant Parkinson's disease patients; sd, standard deviation; sdaMCl, single domain amnestic mild cognitive impairment; sLRP, stimulus-locked lateralized readiness potential; YA, young adult; YO, young-old adults.

\section{$\mathrm{MCl}$ on Contextual Processing - Behavioral and Neuroanatomical Data}

We were unable to find any studies in the literature that examined the effects of MCI on $\mathrm{CP}$ from a neuroanatomical perspective. However, from a behavioral perspective, mdaMCI patients took a longer time than sdaMCI patients and age-matched controls in eliciting a motor response when presented with a task-relevant stimulus. ${ }^{85}$

\section{Alzheimer's Disease on Contextual Processing - Electrophysiology Data}

We were unable to find any electrophysiology-related studies in the literature that examined the effects of $\mathrm{AD}$ on $\mathrm{CP}$.

\section{Alzheimer's Disease on Contextual Processing - Behavioral and Neuroanatomical Data}

Current literature suggests a complete lack of neuroanatomical studies in understanding $\mathrm{CP}$ in $\mathrm{AD}$. The sole study of the research line that examined the effects of $\mathrm{AD}$ on $\mathrm{CP}$ enrolled $26 \mathrm{AD}$ patients and 43 age matched control participants and this was purely behavioral. ${ }^{88}$ The researchers observed that $\mathrm{AD}$ patients were unable to maintain contextual information for $5000 \mathrm{~ms}$ (Table 1C). In the study, AD patients made more errors on $B X$ trials in contrast to $A X, A Y$, and $B Y$ trials and exhibited no response latency for the $B X$ trial, compared with age-matched controls. This was interpreted by the authors as: instead of taking the needed extra processing time on $B X$ trials to inhibit the inappropriate response tendencies associated with the $\mathrm{X}$ probe, $\mathrm{AD}$ patients simply succumbed to the proberelated interference and generated an error response. The authors further interpreted that $\mathrm{AD}$ patients were unable to utilize contextual information to execute task-related behaviours due to an impaired proactive control due to the fact that the $B X$ trial of the AX-CPT task is used to index proactive control. ${ }^{88}$ This suggests that proactive control in further impaired in $\mathrm{AD}$ than in normal aging.

\section{Parkinson's Disease on Contextual Processing - Electrophysiology Data}

Five studies explored the effects of PD on contextual processing, and each restricted the enrolment to PD patients without dementia (Table 1D). Three studies 
repeatedly showed that $\mathrm{PD}$ patients were able to detect targets but unable to utilize the contextual information (ie, a predictive sequence to help them generate a faster response in a subsequent trial). ${ }^{25,89,90}$ Based on the authors' interpretation, the extensive connections in PD patients' frontal networks inhibited the rate at which information was relayed, hence the underperformance on the processing of contexts in this population. ${ }^{89,90}$ Fogelson et al also compared CP performance involving PD and schizophrenic patients, and reported that both patient groups had abnormal network changes when processing context-dependent stimuli, specifically weaker frontaltemporal-parietal connections. ${ }^{25}$ Interestingly, another study reported that proactive control was preserved amongst PD patients, as they showed the ability to adjust control mechanisms to better adapt to future response conflict. ${ }^{91}$ The study also showed that as motor symptom severity increased, online cognitive control was decreased in the PD patient participants, although proactive control remained unaffected. ${ }^{91}$ Yet, another study observed that proactive inhibition was preserved amongst early-stage PD patients whereas reactive inhibition was reduced. ${ }^{92}$ Collectively, these studies suggest that proactive control is spared amongst PD patients.

\section{Parkinson's Disease on Contextual Processing - Behavioral and Neuroanatomical Data}

We were unable to find any studies in the literature that examined the effects of PD on CP from a neuroanatomical perspective. However, from a behavioral perspective, the non-demented PD patients showed robust context maintenance abilities (proactive control), but weakened context adjustment abilities (reactive control). For instance, Di Caprio et al observed that PD patients struggled with inhibiting a response when presented with contradicting information. ${ }^{92}$ Fogelson et al noted that PD patients had issues differentiating task-relevant from task-irrelevant information, which could contribute to the decline in reactive control abilities seen in this population. ${ }^{89}$

\section{Discussion}

We studied the literature on contextual processing concerning the impacts of normal and accelerated aging. The available data to date have revealed some important findings. As summarized in Figure 2, older adults had a delayed onset and reduced amplitude of electrophysiological response to information detection, comparison, and execution. CP is further impaired in $\mathrm{AD}$, specifically in terms of the proactive control mechanism, whereas PD largely affects the reactive control mechanism of CP. Depending on subtype, the effect of MCI can be more heterogeneous, although slower initiating, processing, and motor responding appear to be typical. The information has clinical and healthcare implications. As an integral component of executive control, CP is fundamental in support of daily living, allowing individuals to internally interpret environmental cues to guide their thoughts and behavior through the formation of an internal representation of context, remembering the information in working memory, and updating of context to adjust to the environment. $^{11,93,94}$

Studies consistently suggested that aging is associated with marked changes in the $\mathrm{P} 3 \mathrm{a}, \mathrm{P} 3 \mathrm{~b}$, and $\mathrm{CNV}$ waveforms induced by CP tasks, with delayed onset and reduced amplitudes as being common (Table 1). ${ }^{10,30,40,65-68,70,72,73,95,96}$ Based on these differences, it has been suggested that electrophysiological markers may be developed in support of clinical decision making. ${ }^{14}$ Aging is also associated with reduced inhibition toward irrelevant stimuli and older adults recruit additional neural resources to perform $\mathrm{CP}$ tasks. ${ }^{63,74,78}$ It is clear that older adults are more reliant on their frontal structures than younger adults with $\mathrm{CP}$, especially the $\mathrm{PFC},{ }^{68,77}$ in accordance with the "guided activation theory of PFC function," in suggesting that frontal dopamine system aids in setting and achieving goals, which is less efficient in older adults so that further engagement of the PFC coordination is seen in this population.

The only study that compared the effects of AD on $\mathrm{CP}$ was based on behavioral data and reported that proactive control was severely impaired in the AD patients, whilst reactive control remained relatively stable. ${ }^{88}$ Indeed, proactive control may be more effortful and cognitively demanding than reactive control in that the latter is only active on an "as-needed" basis, specifically when an interference is encountered. ${ }^{97,98}$ Furthermore, the neural regions supporting proactive control (ie, the anterior attention system including the frontal eye field) deteriorate faster than those supporting reactive control (ie, the posterior attention system including the parietal cortex and the temporoparietal junction). ${ }^{78,99-101}$ The hallmark hippocampi and the medial temporal atrophy in AD can affect information maintenance with working memory. Neuroimaging and electrophysiology research are needed to determine whether $\mathrm{AD}$ involves further changes in $\mathrm{P} 3 \mathrm{a}$, $\mathrm{P} 3 \mathrm{~b}, \mathrm{CNV}$, and $\mathrm{N} 2$ waveforms than normal aging. 


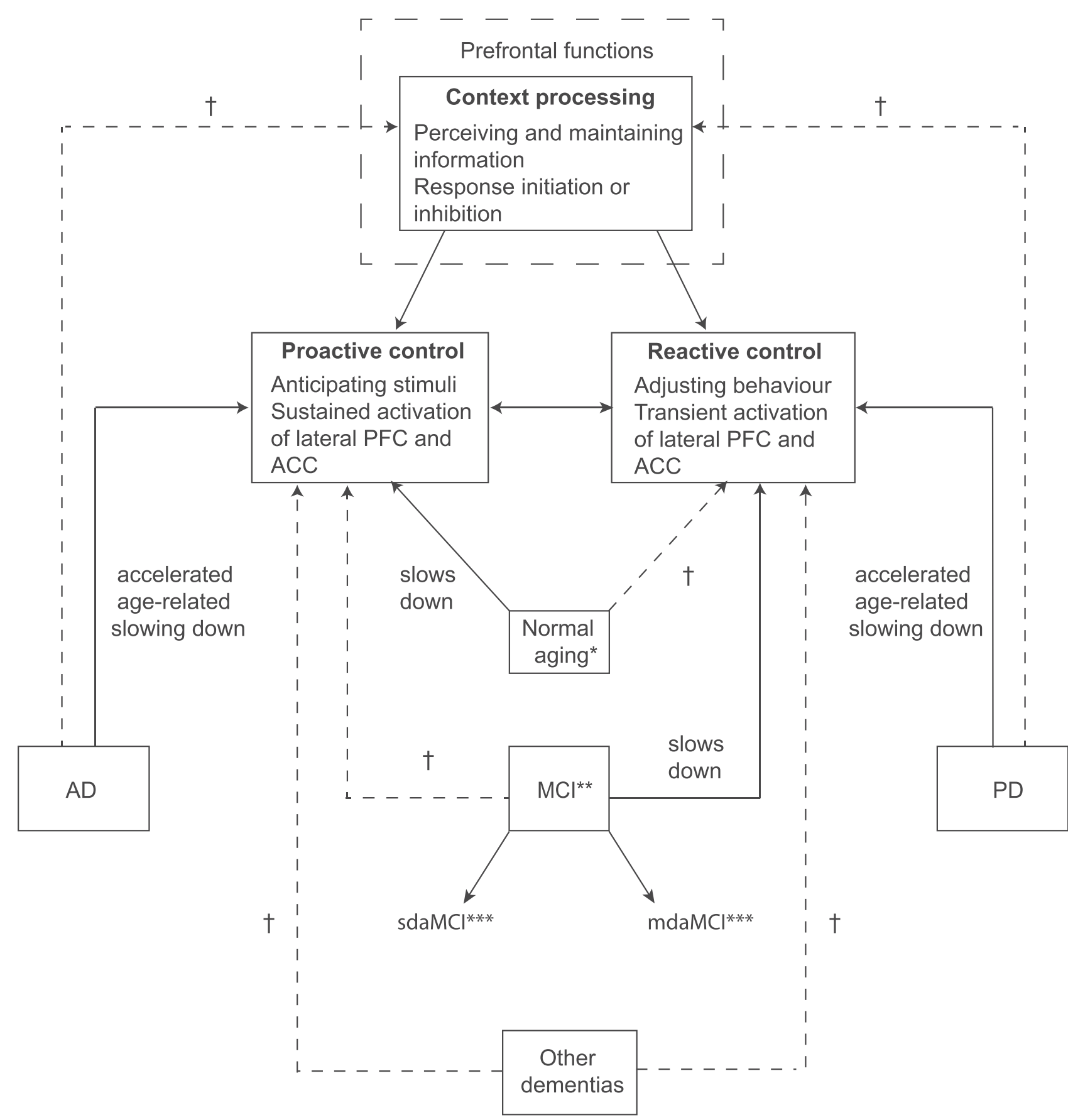

Figure 2 Summary of current status of contextual processing research in relation to normal and accelerated aging. *lt remains to be determined the other effects that normal aging could have on context processing. **It remains to be determined the other effects that $\mathrm{MCl}$ could have on context processing. ${ }^{* *} \mathrm{mdaMCl}$ patients perform worse than sdaMCl patients. $†$ Unknown effects.

Abbreviations: $A C C$, anterior cingulate cortex; $A D$, Alzheimer's Disease; aMCl, amnestic mild cognitive impairment; $C P$, context processing; mdaMCl, multiple domain amnestic mild cognitive impairment; PD, Parkinson's Disease; PFC, prefrontal cortex; sdaMCl, single domain amnestic mild cognitive impairment.

Compared to AD, CP was better studied for PD but limited to older patients without dementia, with results spanning both behavioral and electrophysiological aspects. It is clear that PD affects the utilization of contextual information to prepare and execute a response, due to the over-excessive frontal network connections, preventing effective cross-communication between cortical regions. ${ }^{25,89,90}$ As a result, PD patients without dementia exhibited a decline in their reactive control performance, most likely related to the loss of dopaminergic neurons in their basal ganglia, preventing effective motor abilities. On the other hand, proactive control remained relatively intact 
for these PD patients, ${ }^{91,92}$ opposite to what is observed in $\mathrm{AD}$ and mdaMCI patients who experienced declines in memory and other cognitive domains.

$\mathrm{CP}$ in MCI may be more complicated to study due to highly heterogeneous conditions. The studies under the review have all been on amnestic MCI patients, who showed a general slowness with contextual information processing in contrast to normal aging. Several studies contrasted the mdaMCI and sdaMCI subtypes: typical, mdaMCI patients exhibit more profound brain activity changes, explained by the decreased attentional resources in mdaMCI for processing task-relevant stimuli. $^{82-87}$ The pace to initiate a motor response was also slower than normal aging, seen with a relatively lower LRP amplitudes (an ERP marker for motor processes). ${ }^{84}$ The observation that a prolonged N2cc latency characterize the multi-domain amnestic MCI also suggests a deficit in the executive function of the MCI group. ${ }^{86}$ The information can be useful for early differential diagnoses and effective intervention, considering that MCI represents the greatest risk for dementia.

Several caveats apply to our study. First, data presented were based on a small number of publications, most of which enrolled a small number of participants. We also did not carry out a systematic review and may not have a complete coverage of the topic. For instance, only one study was found for $\mathrm{CP}$ and $\mathrm{AD}$ and it was purely behavioural with no EEG or imaging data, demonstrating how novel this topic is. When more data become available, more sophisticated screening methodologies and data analysis can become feasible. Additionally, given the current paucity of available clinical data, it is not understood whether the present findings can be reliably generalized. It is anticipated that the needed future research will reveal additional data to improve the understanding about the disease impact with increased sample sizes and more sophisticated study designs.

Also, we limited the scope of the review to $\mathrm{CP}$ and excluded publications on the other related cognitive aspects, such as semantic processing, sensory perception, and attention. Clearly, cognitive domains are associated with each other, all of which being critical to our daily living activities. Similarly, we cannot expect neurocognitive disorders or the deficits of normal aging to affect particular cognitive domains in isolation. Meanwhile, studies typically have a focused purpose of investigating a specific cognitive domain and indeed several domains including memory, attention, and executive function have each been well reviewed previously. ${ }^{3,102}$ In terms of $\mathrm{CP}$, it is a primary part of multiple cognitive processes and shares with multiple common PFC presentations such as dorsolateral $\mathrm{PFC}$ and lateral $\mathrm{PFC},{ }^{4,10,16-18}$ making it even more difficult for focused investigation. For this reason, the studies under review are particularly plausible, owing to the careful design and data curating to allow the critical information. Further development and clinical translation of $\mathrm{CP}$ research will also rely on future methodology and technology breakthroughs.

Even with the limitations, our work contributes to the research field by providing the first review that synthesizes recent findings on $\mathrm{CP}$. The study suggests that $\mathrm{CP}$ declines with age and is further impaired by neurodegenerative diseases, including $\mathrm{AD}, \mathrm{PD}$, and $\mathrm{MCI}$ with characteristic patterns (Figure 2). This knowledge can potentially benefit clinical decision-making in the realm of aging and neurocognitive disorders. Moreover, our study draws attention to a clear need for future research on $\mathrm{CP}$ such as implementing neuroimaging technologies. Further, it revealed a knowledge gap about the effects of other dementias on $\mathrm{CP}$, other than AD (Figure 2). Many of these including frontotemporal dementia, Lewy body dementia, and vascular dementia have unique neuropathology and clinical representation and we hypothesize that they would affect CP. For instance, vascular dementia is characterized with widespread white matter connectivity, ${ }^{103}$ and this will likely affect information transmission of CP.

Taken together, previous research has clearly demonstrated the importance of contextual processing in older adults with their adaptation in daily living environment. A reduction in $\mathrm{CP}$ has been found to affect widespread aspects of their personal and social lives including speech and communication, reasoning, recognition, memory, judgment and decision-making. ${ }^{103-107}$ This raises concern to expand this important but largely understudied area of CP in aging. It is anticipated that future research will be able to apply valid innovative methods and technologies ${ }^{17-19}$ and produce the needed data to investigate $\mathrm{CP}$. The needed data on $\mathrm{CP}$ in $\mathrm{MCI}, \mathrm{AD}$, and other neurodegenerative conditions will help provide important new insights for clinical practice, to early diagnose and control the symptoms and risk factors, and effectively manage the diseases and prevent cognitive consequences. The information will also be valuable for improved care of older adults with sensible supportive contexts. 


\section{Conclusion}

Contextual processing is a unique component of working memory and executive function critical for daily living. Available data have revealed characteristic behavioral, neural activation, brain waveforms, and structural changes of $\mathrm{CP}$ in normal aging while its impairments in agingrelated neurodegenerative disorders are little known, other than reduced proactive control in $\mathrm{AD}$ and reactive control in PD. A general trend for $\mathrm{CP}$ performance in $\mathrm{MCI}$ patients is slower processing and movement initiation. The current situation calls for future research to enrich the knowledge in this field for improved intervention/preventative strategies.

\section{Acknowledgments}

This study was supported by research funding from Surrey Health Technology District and Surrey Hospital Foundation (FHG2017-001). The authors acknowledge Riley Chang for help with manuscript format, Fraser Health Department of Evaluation and Research Services for administrative support, and the three anonymous reviewers for their critical comments on the initial submission.

\section{Author Contributions}

All authors made substantial contributions to conception and design, acquisition of data, or analysis and interpretation of data; took part in drafting the article or revising it critically for important intellectual content; agreed to submit to the current journal; gave final approval of the version to be published; and agree to be accountable for all aspects of the work.

\section{Disclosure}

The authors report no conflicts of interest in this work.

\section{References}

1. Hasher L, Zacks RT. Working memory, comprehension, and aging: a review and a new view. Psychol LearningMotivation. 1988;Jan (22):193-225.

2. Bäckman L, Jones S, Berger AK, Laukka EJ, Small BJ. Multiple cognitive deficits during the transition to Alzheimer's disease. $J \quad$ Intern Med. 2004;256(3):195-204. doi:10.1111/j.13652796.2004.01386.x

3. Perry RJ, Hodges JR. Attention and executive deficits in Alzheimer's disease: a critical review. Brain. 1999;122(3):383-404. doi:10.1093/ brain/122.3.383

4. Barch DM, Carter CS, Braver TS, et al. Selective deficits in prefrontal cortex function in medication-naive patients with schizophrenia. Arch Gen Psychiatry. 2001;58(3):280-288. doi:10.1001/archpsyc.58.3.280
5. Cohen JD, Servan-Schreiber D. Context, cortex, and dopamine: a connectionist approach to behavior and biology in schizophrenia. Psychol Rev. 1992;99(1):45. doi:10.1037/0033-295X.99.1.45

6. Kirova AM, Bays RB, Lagalwar S. Working memory and executive function decline across normal aging, mild cognitive impairment, and Alzheimer's disease. Biomed Res Int. 2015;15:2015.

7. Pompili M, Innamorati M, Lamis DA, et al. The associations among childhood maltreatment, "male depression" and suicide risk in psychiatric patients. Psychiatry Res. 2014;220(1-2):571-578. doi:10.1016/j.psychres.2014.07.056

8. Serafini G, Gonda X, Canepa G, et al. Extreme sensory processing patterns show a complex association with depression, and impulsivity, alexithymia, and hopelessness. J Affect Disord. 2017;1(210):249-257. doi:10.1016/j.jad.2016.12.019

9. Payne BR, Silcox JW. Aging, context processing, and comprehension. In: Psychology of Learning and Motivation. Vol. 71. Academic Press; 2019:215-264.

10. Schmitt H, Ferdinand NK, Kray J. Age-differential effects on updating cue information: evidence from event-related potentials. Cogn Affect Behav Neurosci. 2014;14(3):1115-1131. doi:10.3758/s13415-014-0268-9

11. Braver TS, Barch DM. A theory of cognitive control, aging cognition, and neuromodulation. Neurosci Biobehav Rev. 2002;26(7):809-817. doi:10.1016/S0149-7634(02)00067-2

12. Fogelson N. Neural correlates of local contextual processing across stimulus modalities and patient populations. Neurosci Biobehav Rev. 2015;1(52):207-220.

13. Ghosh Hajra S, Liu CC, Song X, et al. Developing brain vital signs: initial framework for monitoring brain function changes over time. Front Neurosci. 2016;12(10):211.

14. Hajra SG, Liu CC, Song X, et al. Accessing knowledge of the 'here and now': a new technique for capturing electromagnetic markers of orientation processing. J Neural Eng. 2018;16 (1):016008. doi:10.1088/1741-2552/aae91e

15. Hajra SG, Gopinath S, Liu CC, et al. Enabling event-related potential assessments using low-density electrode arrays: a new technique for denoising individual channel EEG data. In 2020 IEEE International IOT, Electronics and Mechatronics Conference (IEMTRONICS) 2020 Sep 9. (pp. 1-7). IEEE.

16. Braver TS, Gray JR, Burgess GC. Explaining the many varieties of working memory variation: dual mechanisms of cognitive control. Variation Working Memory. 2007;3(75):106.

17. Braver TS. The variable nature of cognitive control: a dual mechanisms framework. Trends Cogn Sci. 2012;16(2):106-113. doi:10.1016/j.tics.2011.12.010

18. De Pisapia N, Braver TS. A model of dual control mechanisms through anterior cingulate and prefrontal cortex interactions. Neurocomputing. 2006;69(10-12):1322-1326. doi:10.1016/j. neucom.2005.12.100

19. Mesulam MM. From sensation to cognition. Brain. 1998;121 (6):1013-1052. doi:10.1093/brain/121.6.1013

20. Huettel SA, Song AW, McCarthy G. Decisions under uncertainty: probabilistic context influences activation of prefrontal and parietal cortices. J Neurosci. 2005;25(13):3304-3311. doi:10.1523/ JNEUROSCI.5070-04.2005

21. MacDonald AW, Cohen JD, Stenger VA, Carter CS. Dissociating the role of the dorsolateral prefrontal and anterior cingulate cortex in cognitive control. Science. 2000;288(5472):1835-1838. doi:10.1126/science.288.5472.1835

22. Miller EK, Cohen JD. An integrative theory of prefrontal cortex function. Annu Rev Neurosci. 2001;24(1):167-202. doi:10.1146/ annurev.neuro.24.1.167

23. MacDonald III AW, Carter CS, Kerns JG, et al. Specificity of prefrontal dysfunction and context processing deficits to schizophrenia in never-medicated patients with first-episode psychosis. Am J Psychiatry. 2005;162(3):475-484. doi:10.1176/appi.ajp.162.3.475 
24. Fogelson N, Wang X, Lewis JB, et al. Multimodal effects of local context on target detection: evidence from P3b. J Cogn Neurosci. 2009;21(9):1680-1692. doi:10.1162/jocn.2009.21071

25. Fogelson N, Li L, Li Y, et al. Functional connectivity abnormalities during contextual processing in schizophrenia and in Parkinson's disease. Brain Cong. 2013;82(3):243-253. doi:10.1016/j.bandc.2013.05.001

26. Barch DM, Braver TS, Nystrom LE, et al. Dissociating working memory from task difficulty in human prefrontal cortex. Neuropsychologia. 1997;35(10):1373-1380. doi:10.1016/S00283932(97)00072-9

27. Polich J, Criado JR. Neuropsychology and neuropharmacology of P3a and P3b. Int J Psychophysiol. 2006;60(2):172-185.

28. Poulsen C, Luu P, Davey C, Tucker DM. Dynamics of task sets: evidence from dense-array event-related potentials. Cong Brain Res. 2005;24(1):133-154. doi:10.1016/j.cogbrainres.2005.01.008

29. Squires KC, Wickens C, Squires NK, Donchin E. The effect of stimulus sequence on the waveform of the cortical event-related potential. Science. 1976;193(4258):1142-1146. doi:10.1126/ science. 959831

30. Squires KC, Squires NK, Hillyard SA. Decision-related cortical potentials during an auditory signal detection task with cued observation intervals. J Exp Psychol Hum Percept Perform. 1975;1(3):268. doi:10.1037/0096-1523.1.3.268

31. Polich J, editor. Detection of Change: Event-Related Potential and fMRI Findings. Norwell, MA: Kluwer Academic Publishers; 2003.

32. Verleger R. Event-related potentials and cognition: a critique of the context updating hypothesis and an alternative interpretation of P3. Behav Brain Sci. 1988;11(3):343-356. doi:10.1017/ S0140525X00058015

33. Chao LL, Nielsen-Bohlman L, Knight RT. Auditory event-related potentials dissociate early and late memory processes. Electroencephalogr Clin Neurophysiol. 1995;96(2):157-168. doi:10.1016/0168-5597(94)00256-E

34. Squires KC, Hillyard SA, Lindsay PH. Vertex potentials evoked during auditory signal detection: relation to decision criteria. Percept Psychophys. 1973;14(2):265-272. doi:10.3758/ BF03212388

35. Johnson R. A triarchic model of P300 amplitude Psychophysiology. 1986. doi:10.1111/j.1469-8986.1986.tb00649.x

36. Kok A. On the utility of $\mathrm{P} 3$ amplitude as a measure of processing capacity. Psychophysiology. 2001;38(3):557-577. doi:10.1017/ S0048577201990559

37. Duncan-Johnson CC. Young Psychophysiologist Award Address, 1980: P300 latency: a new metric of information processing. Psychophysiology. 1981;18(3):207-215. doi:10.1111/j.14698986.1981.tb03020.x

38. Hillyard SA, Kutas M. Electrophysiology of cognitive processing. Ann Rev Psychol. 1983;34(1):33-61. doi:10.1146/annurev. ps.34.020183.000341

39. Kutas M, McCarthy G, Donchin E. Augmenting mental chronometry: the P300 as a measure of stimulus evaluation time. Science. 1977;197(4305):792-795. doi:10.1126/science.887923

40. Verleger R, Jaśkowski P, Wascher E. Evidence for an integrative role of $\mathrm{P} 3 \mathrm{~b}$ in linking reaction to perception. J Psychophysiol. 2005;19(3):165-181. doi:10.1027/0269-8803.19.3.165

41. Duncan CC, Barry RJ, Connolly JF, et al. Event-related potentials in clinical research: guidelines for eliciting, recording, and quantifying mismatch negativity, P300, and N400. Clin Neurophysiol. 2009;120(11):1883-1908.

42. Dias EC, Butler PD, Hoptman MJ, Javitt DC. Early sensory contributions to contextual encoding deficits in schizophrenia. Arch Gen Psychiatry. 2011;68(7):654-664. doi:10.1001/ archgenpsychiatry.2011.17
43. Folstein JR, Van Petten C. Influence of cognitive control and mismatch on the N2 component of the ERP: a review. Psychophysiology. 2008;45(1):152-170. doi:10.1111/j.1469-8986.2007.00602.x

44. Nieuwenhuis $S$, Yeung $N$, Van Den Wildenberg $W$, Ridderinkhof KR. Electrophysiological correlates of anterior cingulate function in a go/no-go task: effects of response conflict and trial type frequency. Cong Affect Behav Neurosci. 2003;3 (1):17-26. doi:10.3758/CABN.3.1.17

45. Kray J, Eppinger B, Mecklinger A. Age differences in attentional control: an event-related potential approach. Psychophysiology. 2005;42(4):407-416. doi:10.1111/j.1469-8986.2005.00298.x

46. Damen EJ, Brunia $\mathrm{CH}$. Is a stimulus conveying task-relevant information a sufficient condition to elicit a stimulus-preceding negativity? Psychophysiology. 1994;31(2):129-139. doi:10.1111/ j.1469-8986.1994.tb01033.x

47. Gomez CM, Marco J, Grau C. Preparatory visuo-motor cortical network of the contingent negative variation estimated by current density. Neuroimage. 2003;20(1):216-224. doi:10.1016/S10538119(03)00295-7

48. Gratton G, Coles MG, Sirevaag EJ, Eriksen CW, Donchin E. Preand poststimulus activation of response channels: a psychophysiological analysis. J Exp Psychol Hum Percept Perform. 1988;14(3):331. doi:10.1037//0096-1523.14.3.331

49. Praamstra P. Prior information of stimulus location: effects on ERP measures of visual selection and response selection. Brain Res. 2006;1072(1):153-160. doi:10.1016/j.brainres.2005.11.098

50. Polizzotto NR, Hill-Jarrett T, Walker C, Cho RY. Normal development of context processing using the AXCPT paradigm. PLoS One. 2018;13(5):e0197812. doi:10.1371/journal.pone.0197812

51. Cohen JD, Barch DM, Carter CS, Servan-Schreiber D. Schizophrenic deficits in the processing of context: converging evidence from three theoretically motivated cognitive tasks. J Abnorm Psychol. 1999;108(1):120-133. doi:10.1037/0021843X.108.1.120

52. Daigneault S, Braün CM, Whitaker HA. An empirical test of two opposing theoretical models of prefrontal function. Brain Cogn. 1992;19(1):48-71. doi:10.1016/0278-2626(92)90037-M

53. Hartman M, Hasher L. Aging and suppression: memory for previously relevant information. Psychol Aging. 1991;6(4):587. doi:10.1037/0882-7974.6.4.587

54. Williams BR, Ponesse JS, Schachar RJ, Logan GD, Tannock R. Development of inhibitory control across the life span. Dev Psychol. 1999;35(1):205. doi:10.1037/0012-1649.35.1.205

55. Casey BJ, Castellanos FX, Giedd JN, et al. Implication of right frontostriatal circuitry in response inhibition and attention-deficit/ hyperactivity disorder. J Am Acad Child Adolesc Psychiatry. 1997;36(3):374-383. doi:10.1097/00004583-199703000-00016

56. Wylie GR, Javitt DC, Foxe JJ. Task switching: a high-density electrical mapping study. Neuroimage. 2003;20(4):2322-2342. doi:10.1016/j.neuroimage.2003.08.010

57. Mancini C, Modugno N, Santilli M, et al. Unilateral stimulation of subthalamic nucleus does not affect inhibitory control. Front Neurol. 2019;7(9):1149. doi:10.3389/fneur.2018.01149

58. Lehle C, Hübner R. On-the-fly adaptation of selectivity in the flanker task. Psychon Bull Rev. 2008;15(4):814-818. doi:10.3758/ PBR.15.4.814

59. West R, Bowry R, McConville C. Sensitivity of medial frontal cortex to response and nonresponse conflict. Psychophysiology. 2004;41(5):739-748. doi:10.1111/j.1469-8986.2004.00205.x

60. Escera C, Alho K, Winkler I, Näätänen R. Neural mechanisms of involuntary attention to acoustic novelty and change. J Cogn Neurosci. 1998;10(5):590-604. doi:10.1162/089892998562997

61. Trewartha KM, Penhune VB, Li KZ. Movement kinematics of prepotent response suppression in aging during conflict adaptation. J Gerontol Ser B. 2011;66(2):185-194. doi:10.1093/ geronb/gbq090 
62. Van der Lubbe RH, Verleger R. Aging and the Simon task. Psychophysiology. 2002;39(1):100-110. doi:10.1111/14698986.3910100

63. Hemsley DR. The schizophrenic experience: taken out of context? Schizophr Bull. 2005;31(1):43-53. doi:10.1093/schbul/sbi003

64. Baddeley A. The episodic buffer: a new component of working memory? Trends Cogn Sci. 2000;4(11):417-423. doi:10.1016/ S1364-6613(00)01538-2

65. Fogelson N, Shah M, Bonnet-Brilhault F, Knight RT. Electrophysiological evidence for aging effects on local contextual processing. Cortex. 2010;46(4):498-506. doi:10.1016/j. cortex.2009.05.007

66. Gaeta H, Friedman D, Hunt G. Stimulus characteristics and task category dissociate the anterior and posterior aspects of the novelty P3. Psychophysiology. 2003;40(2):198-208. doi:10.1111/ 1469-8986.00022

67. Hohnsbein J, Falkenstein M, Hoormann J, Blanke L. Effects of crossmodal divided attention on late ERP components. I. Simple and choice reaction tasks. Electroencephalogr Clin Neurophysiol. 1991;78(6):438-446. doi:10.1016/0013-4694(91)90061-8

68. Fjell AM, Walhovd KB. Life-span changes in P3a. Psychophysiology. 2004;41(4):575-583. doi:10.1111/j.14698986.2004.00177.x

69. Wetzel N, Schröger E. Cognitive control of involuntary attention and distraction in children and adolescents. Brain Res. 2007;25 (1155):134-146. doi:10.1016/j.brainres.2007.04.022

70. Hämmerer D, Li SC, Müller V, Lindenberger U. An electrophysiological study of response conflict processing across the lifespan: assessing the roles of conflict monitoring, cue utilization, response anticipation, and response suppression. Neuropsychologia. 2010;48 (11):3305-3316. doi:10.1016/j.neuropsychologia.2010.07.014

71. West R, Schwarb $H$. The influence of aging and frontal function on the neural correlates of regulative and evaluative aspects of cognitive control. Neuropsychology. 2006;20(4):468. doi:10.1037/ 0894-4105.20.4.468

72. Rae CL, Hughes LE, Anderson MC, Rowe JB. The prefrontal cortex achieves inhibitory control by facilitating subcortical motor pathway connectivity. J Neurosci. 2015;35(2):786-794. doi:10.1523/JNEUROSCI.3093-13.2015

73. Steele VR, Aharoni E, Munro GE, et al. A large scale $(\mathrm{N}=102)$ functional neuroimaging study of response inhibition in a $\mathrm{Go}$ / NoGo task. Behav Brain Res. 2013;1(256):529-536. doi:10.1016/ j.bbr.2013.06.001

74. Manard M, François S, Phillips C, Salmon E, Collette F. The neural bases of proactive and reactive control processes in normal aging. Behav Brain Res. 2017;1(320):504-516. doi:10.1016/j. bbr.2016.10.026

75. Botvinick MM, Braver TS, Barch DM, Carter CS, Cohen JD. Conflict monitoring and cognitive control. Psychol Rev. 2001;108 (3):624. doi:10.1037/0033-295X.108.3.624

76. Egner T, Hirsch J. Cognitive control mechanisms resolve conflict through cortical amplification of task-relevant information. Nat Neurosci. 2005;8(12):1784-1790. doi:10.1038/nn1594

77. Paxton JL, Barch DM, Racine CA, Braver TS. Cognitive control, goal maintenance, and prefrontal function in healthy aging. Cereb Cortex. 2008;18(5):1010-1028. doi:10.1093/cercor/bhm135

78. Bugg JM. Evidence for the sparing of reactive cognitive control with age. Psychol Aging. 2014;29(1):115. doi:10.1037/a0035270

79. Rush BK, Barch DM, Braver TS. Accounting for cognitive aging: context processing, inhibition or processing speed? Neuropsychol Dev Cogn B Aging Neuropsychol Cong. 2006;13(3-4):588-610. doi:10.1080/13825580600680703

80. Braver TS, Paxton JL, Locke HS, Barch DM. Flexible neural mechanisms of cognitive control within human prefrontal cortex. Proc Natl Acad of Sci. 2009;106(18):7351-7356. doi:10.1073/pnas.0808187106
81. Braver TS, Barch DM, Keys BA, et al. Context processing in older adults: evidence for a theory relating cognitive control to neurobiology in healthy aging. J Exp Psychol Gen. 2001;130 (4):746. doi:10.1037/0096-3445.130.4.746

82. Cid-Fernández S, Lindin M, Diaz F. Effects of amnestic mild cognitive impairment on $\mathrm{N} 2$ and $\mathrm{P} 3$ Go/NoGo ERP components. J Alzheimer's Dis. 2014;38(2):295-306. doi:10.3233/JAD-130677

83. Ramos-Goicoa M, Galdo-Alvarez S, Diaz F, Zurron M. Effect of normal aging and of mild cognitive impairment on event-related potentials to a Stroop color-word task. J Alzheimer's Dis. 2016;52 (4):1487-1501. doi:10.3233/JAD-151031

84. Cid-Fernández S, Lindin M, Diaz F. Neurocognitive and behavioral indexes for identifying the amnestic subtypes of mild cognitive impairment. J Alzheimer's Dis. 2017;60(2):633-649. doi:10.3233/JAD-170369

85. Cespón J, Galdo-Álvarez S, Diaz F. Electrophysiological correlates of amnestic mild cognitive impairment in a Simon task. PLoS One. 2013;8(12):e81506. doi:10.1371/journal.pone.0081506

86. Cespón J, Galdo-Álvarez S, Díaz F. Inhibition deficit in the spatial tendency of the response in multiple-domain amnestic mild cognitive impairment. An Event-Related Potential Study Frontiers in Aging Neuroscience. 2015;6(7):68.

87. Cid-Fernández S, Lindín M, Díaz F. Stimulus-locked lateralized readiness potential and performance: useful markers for differentiating between amnestic subtypes of mild cognitive impairment. J Prev Alzheimers Dis. 2017;Jan(4):21-28.

88. Braver TS, Satpute AB, Rush BK, Racine CA, Barch DM. Context processing and context maintenance in healthy aging and early stage dementia of the Alzheimer's type. Psychol Aging. 2005;20(1):33. doi:10.1037/0882-7974.20.1.33

89. Fogelson N, Fernandez-del-Olmo M, Santos-Garcia D. Contextual processing deficits in Parkinson's disease: the role of the frontostriatal system. Clin Neurophysiol. 2011;122 (3):539-545. doi:10.1016/j.clinph.2010.07.017

90. Li L, Diaz-Brage P, Fernandez-Lago H, Fogelson N. Processing of implicit versus explicit predictive contextual information in Parkinson's disease. Neuropsychologia. 2018;31(109):39-51. doi:10.1016/j.neuropsychologia.2017.12.006

91. Wylie SA, Ridderinkhof KR, Bashore TR, van den Wildenberg WP. The effect of Parkinson's disease on the dynamics of on-line and proactive cognitive control during action selection. J Cong Neurosci. 2010;22(9):2058-2073. doi:10.1162/ jocn.2009.21326

92. Di Caprio V, Modugno N, Mancini C, Olivola E, Mirabella G. Early-stage Parkinson's patients show selective impairment in reactive but not proactive inhibition. Mov Disord. 2020;35 (3):409-418. doi:10.1002/mds.27920

93. Braver TS, Cohen JD. Dopamine, cognitive control, and schizophrenia: the gating model. In: Progress in Brain Research. Vol. 121. Elsevier; 1999:327-349.

94. Braver TS, Cohen JD. On the control of control: the role of dopamine in regulating prefrontal function and working memory. Control Cognitive Processes. 2000;1:713-737.

95. Trewartha KM, Spilka MJ, Penhune VB, Li KZ, Phillips NA. Context-updating processes facilitate response reprogramming in younger but not older adults. Psychol Aging. 2013;28(3):701. doi: $10.1037 / \mathrm{a} 0033843$

96. De Sanctis P, Gomez-Ramirez M, Sehatpour P, Wylie GR, Foxe JJ. Preserved executive function in high-performing elderly is driven by large-scale recruitment of prefrontal cortical mechanisms. Hum Brain Mapp. 2009;30(12):4198-4214. doi:10.1002/ hbm.20839

97. Shiffrin RM, Schneider W. Controlled and automatic human information processing: II. Perceptual learning, automatic attending and a general theory. Psychol Rev. 1977;84(2):127. 
98. Jacoby LL, Lindsay DS, Hessels S. Item-specific control of automatic processes: stroop process dissociations. Psychon Bull Rev. 2003;10(3):638-644. doi:10.3758/BF03196526

99. West RL. An application of prefrontal cortex function theory to cognitive aging. Psychol Bull. 1996;120(2):272. doi:10.1037/ 0033-2909.120.2.272

100. Head D, Buckner RL, Shimony JS, et al. Differential vulnerability of anterior white matter in nondemented aging with minimal acceleration in dementia of the Alzheimer type: evidence from diffusion tensor imaging. Cereb Cortex. 2004;14(4):410-423. doi:10.1093/cercor/bhh003

101. Petersen SE, Posner MI. The attention system of the human brain: 20 years after. Annu Rev Neurosci. 2012;21(35):73-89. doi:10.1146/annurev-neuro-062111-150525

102. Stopford CL, Thompson JC, Neary D, Richardson AM, Snowden JS. Working memory, attention, and executive function in Alzheimer's disease and frontotemporal dementia. Cortex. 2012;48(4):429-446. doi:10.1016/j.cortex.2010.12.002
103. Alber J, Alladi S, Bae HJ, et al. White matter hyperintensities in vascular contributions to cognitive impairment and dementia (VCID): knowledge gaps and opportunities. Alzheimer's Dement (NY). 2019; Jan(5):107-117. doi:10.1016/j.trci.2019.02.001

104. Löckenhoff CE. Aging and decision-making: a conceptual framework for future research-a mini-review. Gerontology. 2018;64 (2):140-148. doi:10.1159/000485247

105. Gutchess AH, Hebrank A, Sutton BP, et al. Contextual interference in recognition memory with age. Neuroimage. 2007;35 (3):1338-1347. doi:10.1016/j.neuroimage.2007.01.043

106. Bayen UJ, Phelps MP, Spaniol J. Age-related differences in the use of contextual information in recognition memory: a global matching approach. $J$ Gerontol $B$ Psychol Sci Soc Sci. 2000;55:131-141. doi:10.1093/geronb/55.3.P131

107. Aydelott J, Leech R, Crinion J. Normal adult aging and the contextual influences affecting speech and meaningful sound perception. Trends Amplif. 2010;14(4):218-232. doi:10.1177/ 1084713810393751
Clinical Interventions in Aging

\section{Publish your work in this journal}

Clinical Interventions in Aging is an international, peer-reviewed journal focusing on evidence-based reports on the value or lack thereof of treatments intended to prevent or delay the onset of maladaptive correlates of aging in human beings. This journal is indexed on PubMed Central, MedLine, CAS, Scopus and the Elsevier
Dovepress

Bibliographic databases. The manuscript management system is completely online and includes a very quick and fair peer-review system, which is all easy to use. Visit http://www.dovepress.com/ testimonials.php to read real quotes from published authors. 